\title{
MODELING APPROACHES TO HYPERSONIC AEROTHERMOELASTICITY WITH APPLICATION TO REUSABLE LAUNCH VEHICLES
}

\author{
B.J. Thuruthimattam, P.P. Friedmann $\dagger$ J.J. McNamara*, and K.G. Powell ${ }^{\ddagger}$ \\ Department of Aerospace Engineering \\ University of Michigan \\ 3001 François-Xavier Bagnoud Bldg., 1320 Beal Ave \\ Ann Arbor, Michigan 48109-2140 \\ Ph: (734) 763-2354 Fax: (734) 763-0578 \\ email: peretzf@umich.edu
}

\begin{abstract}
$\underline{\text { ABSTRACT }}$
The hypersonic aeroelastic and aerothermoelastic problem of a double-wedge airfoil typical crosssection is studied using three different unsteady aerodynamic loads: (1) third-order piston theory, (2) Euler aerodynamics, and (3) Navier-Stokes aerodynamics. Computational aeroelastic response results are used to obtain frequency and damping characteristics, and compared with those from piston theory solutions for a variety of flight conditions. Aeroelastic behavior is studied for $5<M<15$ at altitudes of 40,000 and 70,000 feet. A parametric study of offsets, wedge angles, and static angle of attack is conducted. All the solutions are fairly close below the flutter boundary, and differences between the various models increase when the flutter boundary is approached. For this geometry, differences between viscous and inviscid aeroelastic behavior are not substantial. Results illustrate that aerodynamic heating reduces aeroelastic stability. Applying this approach to a generic vehicle resembling a reusable launch vehicle is also discussed. The results presented serve as a partial validation of the CFL3D code for the hypersonic flight regime.
\end{abstract}

\section{NOMENCLATURE}

a Nondimensional offset between the elastic axis and the midchord

\footnotetext{
${ }^{*}$ Ph.D. Candidate

$\dagger$ François-Xavier Bagnoud Professor of Aerospace Engineering

$\ddagger$ Arthur F. Thurnau Professor of Aerospace Engineering

${ }^{0}$ Copyright (C) 2003 by B. Thuruthimattam, P. Friedmann, J. McNamara, and K. Powell. Published by the American Institute of Aeronautics and Astronautics, Inc. by permission.
}

\author{
$a_{\infty} \quad$ Speed of sound \\ $b \quad$ Semi-chord \\ $c \quad$ Reference length, chord length of \\ double-wedge airfoil \\ $C_{D}, C_{L}, C_{M y}$ Coefficients of drag, lift and \\ moment about the $y$-axis \\ $C_{p P T}, C_{p N S}$ Piston theory pressure coefficient, \\ and CFD Navier-Stokes pressure \\ coefficient respectively \\ $f(x) \quad$ Function describing airfoil surface \\ $f_{1}(), f_{i}()$ Functions relating Mach number and \\ temperature \\ $h \quad$ Airfoil vertical displacement at Elastic \\ Axis \\ $I_{\alpha} \quad$ Mass moment of inertia about the \\ Elastic Axis \\ $K_{\alpha}, K_{h}$ Spring constants in pitch and plunge \\ respectively; $K_{\alpha}=I_{\alpha} \omega_{\alpha}^{2}, K_{h}=m \omega_{h}^{2}$ \\ $L \quad$ Lift per unit span \\ $L_{1}, L_{2}, L_{3}$ First, second and third-order piston \\ theory lift components \\ $M \quad$ free stream Mach number \\ $\mathbf{M}, \mathbf{K}$ Generalized mass and stiffness matrices \\ of the structure \\ $M_{1}, M_{2}, M_{3}$ First, second and third-order \\ piston theory moment components \\ $m \quad$ Mass per unit span \\ $M_{E A} \quad$ Moment per unit span about the Elastic \\ Axis \\ $M_{f} \quad$ Flutter Mach number \\ $n_{m} \quad$ Number of modes used \\ $p \quad$ Pressure \\ $p_{\infty} \quad$ Free-stream pressure \\ Q Generalized force vector for the \\ structure
}




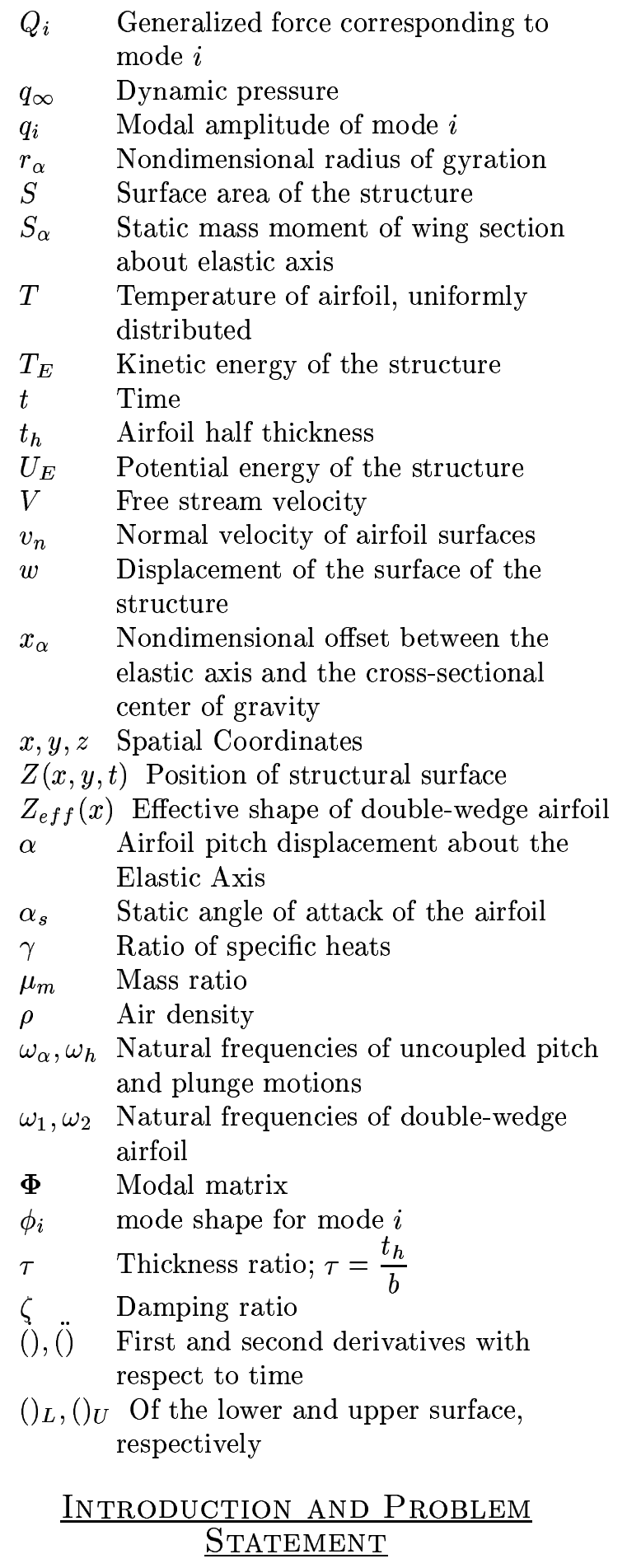

In recent years, renewed activity in hypersonic flight research has been stimulated by the need for a low cost, single-stage-to-orbit (SSTO) or two-stage-toorbit (TSTO) reusable launch vehicle (RLV) and the long term design goal of incorporating air breathing propulsion devices in this class of vehicles. The $\mathrm{X}$ 33 , an example of the former vehicle type, was a $1 / 2$ scale, fully functional technology demonstrator for the full scale VentureStar. Another ongoing hypersonic vehicle research program is the NASA Hyper$\mathrm{X}$ experimental vehicle effort. Other activities are focused on the design of unmanned hypersonic vehicles that meet the needs of the US Air Force. The present study is aimed at enhancing the fundamental understanding of the aeroelastic behavior of vehicles that belong to this category and operate in a typical hypersonic flight envelope.

Vehicles in this category are based on a lifting body design. However, stringent minimum-weight requirements imply a degree of fuselage flexibility. Aerodynamic surfaces, needed for control, are also flexible. Furthermore, to meet the requirement of a flight profile that spans the Mach number range from 0 to 15, the vehicle must withstand severe aerodynamic heating. These factors combine to produce unusual aeroelastic problems that have received only limited attention in the past. Furthermore, it is important to emphasize that testing of aeroelastically scaled wind tunnel models, a conventional practice in subsonic and supersonic flow, is not feasible in the hypersonic regime. Thus, the role of aeroelastic simulations is more important for this flight regime than in any other flight regime.

Previous studies in this area can be separated into several groups. The first group consists of studies focusing on panel flutter, which is a localized aeroelastic problem representing a small portion of the skin on the surface of the hypersonic vehicle. Hypersonic panel flutter has been studied by a number of researchers, focusing on important effects such as aerodynamic heating, ${ }_{1}^{1}$ composite ${ }^{2,3}$ and nonlinear structural models, ${ }^{4}$ and initial panel curvature. ${ }^{5}$ It was noted in Ref. 5 that piston theory may not be appropriate for the hypersonic regime and that hypersonic studies might have to use unsteady aerodynamic loads based on the solution of the NavierStokes equations. A comprehensive review of this research can be found in a recent survey paper. ${ }^{6}$

The second group of studies in this area was motivated by a previous hypersonic vehicle, namely the National Aerospace Plane (NASP). ${ }^{7-13}$ However, some of these studies dealt with the transonic regime, because it was perceived to be quite important. Spain et al. $^{8}$ carried out a flutter analysis of all-movable NASP-like wings with slab and double-wedge airfoils. They found that using effective shapes for the airfoils obtained by adding the boundary layer displacement thickness to the airfoil thickness improved the overall agreement with experiments. Aerothermoelastic analyses of NASPlike vehicles found that aerodynamic heating altered the aeroelastic stability of the vehicle through the 
degradation of material properties and introduction of thermal stresses. ${ }^{11-13}$

The third group of studies is restricted to recent papers that deal with the newer hypersonic configurations such as the $\mathrm{X}-33$ or the $\mathrm{X}-34$. Reference 14 considered the $\mathrm{X}-34$ launch vehicle in free flight at $M=8.0$. The aeroelastic instability of a generic hypersonic vehicle, resembling the $\mathrm{X}-33$, was considered in Ref. 15. It was found that at high hypersonic speeds and high altitudes, the hypersonic vehicle is stable, when piston theory is used to represent the aerodynamic loads. Sensitivity of the flutter boundaries to vehicle flexibility and trim state were also considered. ${ }^{15}$ In another reference, ${ }^{16}$ CFD-based flutter analysis was used for the aeroelastic analysis of the X-43 configuration, using system identification based order reduction of the aerodynamic degrees of freedom. Both the structure and the fluid were discretized using the finite element approach. It was shown that piston theory and ARMA Euler calculations predicted somewhat similar results.

From the studies on various hypersonic vehicles, ${ }^{7,16-18}$ one can identify operating envelopes for each vehicle. A graphical representation of these operating conditions is shown in Fig. 1.

In a recent study, ${ }^{19}$ the authors of this paper described an aeroelastic analysis capability for generic hypersonic vehicles in the Mach number range $0.5<M<15$, using computational aeroelasticity. The computational tool consisted of a combination of the CFL3D code and a finite element model of a generic hypersonic vehicle utilizing NASTRAN. During the validation process of the analysis,${ }^{19}$ the authors studied the aeroelastic behavior of a two dimensional double-wedge airfoil, operating in the Mach number range of $2.0<M<15.0$ at 100,000 feet. The current paper exploits the finding of Ref. 19 which identified the double-wedge airfoil as a remarkably appropriate example for exploring the various computational aspects of hypersonic aeroelasticity. This paper is aimed at exploring fundamental aspects of hypersonic aeroelasticity using computational tools. The specific objectives of the paper are:

1. Generate aeroelastic stability boundaries of a typical cross-section, based on the double-wedge airfoil, in hypersonic flow using piston theory, for comparison with more refined computations.

2. Study the time-step requirements for the reliable computation of the unsteady airloads for this particular problem when using the Euler and Navier-Stokes options of CFL3D.

3. Compare the aeroelastic behavior predicted us- ing piston theory aerodynamics with refined solutions for the same problem, using CFL3D, which calculates the unsteady aerodynamic loads based on complete Euler and NavierStokes solutions.

4. Compare the exact solutions for aeroelastic behavior using the Navier-Stokes-based unsteady airloads, with approximate solutions based on an airfoil shape modified by the presence of a boundary layer.

5. Conduct a parametric study that illustrates the effect of the offset between the elastic axis and the aerodynamic center, the wedge angle of the airfoil, and static angle of attack.

6. Incorporate aerodynamic heating in an approximate manner in order to calculate aerothermoelastic responses.

7. Extend the analysis to a generic hypersonic vehicle that has features resembling a reusable launch vehicle, and present trend-type results.

Finally, it is important to note that these objectives not only enhance our fundamental understanding of hypersonic aeroelasticity, but also make a valuable contribution towards the validation of the CFL3D code for hypersonic flight conditions.

\section{$\underline{\text { Method OF SOLUtion }}$}

The computational aeroelastic solutions in the present study are obtained using the CFL3D code. $^{20}$ The CFL3D code is used to perform both steady and unsteady flow calculations, and to also obtain the aeroelastic transients. The aeroelastic solution utilizes the free vibration modes of the structure.

\section{Euler/Navier-Stokes Solver in CFL3D}

The aeroelastic analysis of the double-wedge airfoil is carried out using the CFL3D code. The code uses an implicit, finite-volume algorithm based on upwind-biased spatial differencing to solve the timedependent Euler and Reynolds-averaged NavierStokes equations. Multigrid and mesh-sequencing are available for convergence acceleration. The algorithm, which is based on a cell-centered scheme, uses upwind-differencing based on either flux-vector splitting or flux-difference splitting, and can sharply capture shock waves. For applications utilizing the thin-layer Navier-Stokes equations, different turbulence models are available. For time-accurate 
problems using a deforming mesh, an additional term accounting for the change in cell-volume is included in the time-discretization of the governing equations. Since CFL3D is an implicit code using approximate factorization, linearization and factorization errors are introduced at every time-step. Hence, intermediate calculations referred to as "subiterations" are used to reduce these errors. Increasing these subiterations improves the accuracy of the simulation, albeit at increased computational cost.

\section{Aeroelastic Option in CFL3D}

The aeroelastic approach underlying the CFL3D code is similar to that described in Refs. 21,22. The equations are derived by assuming that the general motion $w(x, y, t)$ of the structure is described by a finite modal series given by Eqn. (1) below. The functions $\phi_{i}(x, y)$ represent the free vibration modes of the vehicle which are calculated using a finite element approach.

$$
Z(x, y, t)=\sum_{i=1}^{n_{m}} q_{i}(t) \phi_{i}(x, y)
$$

The aeroelastic equations of motion are obtained from Lagrange's equations,

$$
\frac{d}{d t}\left(\frac{\partial T_{E}}{\partial \dot{q}_{i}}\right)-\frac{\partial T_{E}}{\partial q_{i}}+\frac{\partial U_{E}}{\partial q_{i}}=Q_{i}, \quad i=1,2, \ldots
$$

which yield

$$
\mathbf{M} \ddot{q}+\mathbf{K} q=\mathbf{Q}(\mathbf{q}, \dot{\mathbf{q}}, \ddot{\mathbf{q}}), \quad \mathbf{q}^{T}=\left[q_{1} q_{2} \ldots\right]
$$

where the elements of the generalized force vector are given by,

$$
Q_{i}=\frac{\rho V^{2}}{2} c^{2} \int_{S} \phi_{i} \frac{\Delta p d S}{\rho V^{2} / 2 c^{2}}
$$

The aeroelastic equations are written in terms of a linear state-space equation (using a state vector of the form $\left[\begin{array}{llllll}\ldots & \dot{q}_{i-1} & q_{i} & \dot{q}_{i} & q_{i+1} & \ldots\end{array}\right]^{T}$ ) such that a modified state-transition-matrix integrator can be used to march the coupled fluid-structural system forward in time. The fluid forces are coupled with the structural equations of motion through the generalized aerodynamic forces. Thus, a time-history of the modal displacements, modal velocities and generalized forces is obtained.

The aeroelastic capabilities of CFL3D, based on this modal response approach for obtaining the flutter boundary, have been partially validated for the transonic regime for the first AGARD standard aeroelastic configuration for dynamic response,
Wing 445.6. The results of flutter calculations using Euler aerodynamics are given in Ref. 23 and those using Navier-Stokes aerodynamics are given in Ref.24. However, these calculations were limited to the transonic regime.

\section{General Overview of the Solution Process}

The solution of the computational aeroelasticity problem used in the present study is shown in Fig. 2. First, the vehicle geometry is created using CAD software, and from this geometry a mesh generator is used to create a structured mesh for the flow domain around the body. In parallel, an unstructured mesh is created for the finite element model of the structure using the same nodes on the vehicle surface that were used to generate the fluid mesh. Subsequently, the fluid mesh is used to compute the flow around the rigid body using a CFD solver, which consists of the CFL3D code developed by NASA Langley Research Center. The structural mesh is used to obtain the free vibration modes of the structure by finite element analysis using MSC NASTRAN. Nodes on the surface of the geometry in both the structured and unstructured meshes are matched up by their physical coordinates. This correlation is used to obtain the modal displacements at each of the surface nodes in the structured fluid mesh from the unstructured structural mesh. Using the flow solution as an initial condition, and the modal information, an aeroelastic steady state is obtained. For a geometry with vertical symmetry at zero angle of attack, such as the double-wedge airfoil, the aeroelastic steady state is the same as the undeflected state. Next, the structure is perturbed in one or more of its modes by an initial modal velocity condition, and the transient response of the structure is obtained. To determine the flutter conditions at a given altitude, aeroelastic transients are computed at several Mach numbers and the corresponding dynamic pressures. The frequency and damping characteristics of the transient response for a given flight condition and vehicle configuration can be determined from the moving block approach, which analyzes the fourier transform of a discretely sampled transient signal. ${ }^{25}$ This approach applied to the same altitude and vehicle configuration for a range of Mach numbers results in a series of damping values for the system. The flutter Mach number can be estimated from this series by interpolating the damping data points to identify zero damping.

Computational Model for the DOUBLE-WEDGE AIRFOIL 
Few studies ${ }^{26,27}$ have been carried out that validate CFL3D for the hypersonic regime. These studies compared the pressure distributions and static stability derivatives of cones and ogive-cylinder bodies obtained using CFL3D with results obtained using a unified hypersonic/supersonic panel method in the range $3<M<6$.

Validation of the CFL3D code for flutter analysis in the hypersonic regime has never been undertaken. Therefore, reliable results for a simple configuration for which aeroelastic stability and response results could be generated independently, are important. A typical cross-section based on the doublewedge airfoil, shown in Figs. 3 and 4, meets this need. Generating results for this configuration using Euler and Navier-Stokes unsteady aerodynamic loads, and comparing them with results obtained using an independently developed aeroelastic code based on piston theory, provides a reliable means for validating CFL3D in the hypersonic regime.

The Euler and Navier-Stokes computations are carried out using a $225 \times 65$ C-grid with 225 points around the wing and its wake (145 points wrapped around the airfoil itself), and 65 points extending radially outward from the airfoil surface. The computational domain extends one chordlength upstream and six chord lengths downstream, and one chord length to the upper and lower boundaries. For the Navier-Stokes simulations, the Spalart-Allmaras turbulence model was used, along with an adiabatic wall temperature condition. The double-wedge airfoil and a portion of the surrounding computational grid are shown in Fig. 3.

Aeroelastic Model for a Double-Wedge AIRFoIL Using Higher ORder Piston TheORY

Piston theory is an inviscid unsteady aerodynamic theory, that has been used extensively in supersonic and hypersonic aeroelasticity. It provides a pointfunction relationship between the local pressure on the surface of the vehicle and the component of fluid velocity normal to the moving surface. ${ }^{28,29}$ The derivation utilizes the isentropic "simple wave" expression for the pressure on the surface of a moving piston,

$$
\frac{p(x, t)}{p_{\infty}}=\left(1+\frac{\gamma-1}{2} \frac{v_{n}}{a_{\infty}}\right)^{\frac{2 \gamma}{(\gamma-1)}}
$$

where

$$
v_{n}=\frac{\partial Z(x, t)}{\partial t}+V \frac{\partial Z(x, t)}{\partial x}
$$

The expression for piston theory is based on a binomial expansion of Eq. (5), where the order of the expansion is determined by the ratio of $\frac{v_{n}}{a_{\infty}}$. Reference 29 suggested a third-order expansion, since it produced the smallest error of the various orders of expansion used when compared to the limiting values of pressure, namely the "simple wave" and "shock expansion" solutions. The third-order expansion of Eq. (5) yields

$$
\begin{aligned}
p(x, t)-p_{\infty}= & p_{\infty}\left[\gamma \frac{v_{n}}{a_{\infty}}+\frac{\gamma(\gamma+1)}{4}\left(\frac{v_{n}}{a_{\infty}}\right)^{2}\right. \\
& \left.+\frac{\gamma(\gamma+1)}{12}\left(\frac{v_{n}}{a_{\infty}}\right)^{3}\right]
\end{aligned}
$$

An aeroelastic analysis for a typical crosssection for a double-wedge airfoil was developed using Eq. (7) for the unsteady pressure loading. The equations of motion for a typical cross-section, with pitch and plunge degrees of freedom shown in Fig. 4, were obtained from Lagrange's equations.

$$
\begin{aligned}
m \ddot{h}+S_{\alpha} \ddot{\alpha}+K_{h} h & =-L(t) \\
S_{\alpha} \ddot{h}+I_{\alpha} \ddot{\alpha}+K_{\alpha} \alpha & =M_{E A}(t)
\end{aligned}
$$

Assuming small displacements and using Fig. 4 yields

$$
Z(x, t)=-\{h(t)+(x-b a) \alpha(t)\}+f(x)
$$

and

$$
\begin{aligned}
& v_{n U}=-\{\dot{h}+(x-b a) \dot{\alpha}\}+V\left\{-\alpha+\frac{\partial f(x)}{\partial x}\right\} \\
& v_{n L}=\{\dot{h}+(x-b a) \dot{\alpha}\}-V\left\{-\alpha+\frac{\partial f(x)}{\partial x}\right\}
\end{aligned}
$$

where

$$
\begin{aligned}
& \frac{\partial f_{U}(x)}{\partial x}=\tau \quad: \quad-b<x<0 \\
& \frac{\partial f_{U}(x)}{\partial x}=-\tau: 0<x<b \\
& \frac{\partial f_{L}(x)}{\partial x}=-\tau:-b<x<0 \\
& \frac{\partial f_{L}(x)}{\partial x}=\tau: \quad: \quad 0<x<b
\end{aligned}
$$

From Eqs. (7), (10), and (11) the unsteady pressure distribution was determined. The unsteady lift and moment due to this pressure distribution were 
determined from

$$
\begin{array}{llc}
L(t) & = & \int_{-b}^{b}\left(p_{L}(x, t)-p_{U}(x, t)\right) d x \\
M_{E A}(t) & = & -\int_{-b}^{b}(x-b a)\left(p_{L}(x, t)-p_{U}(x, t)\right) d x
\end{array}
$$

The unsteady lift can be written as

$$
L(t)=L_{1}(t)+L_{2}(t)+L_{3}(t)
$$

where,

$$
\begin{aligned}
L_{1}(t)= & 4 p_{\infty} \gamma M b\left\{\frac{\dot{h}}{V}-b a \frac{\dot{\alpha}}{V}+\alpha\right\} \\
L_{2}(t)= & -p_{\infty} \gamma(\gamma+1) M^{2} b^{2} \tau\left(\frac{\dot{\alpha}}{V}\right) \\
L_{3}(t)= & \frac{1}{3} p_{\infty} \gamma(\gamma+1) M^{3} b\left\{\left(\frac{\dot{h}}{V}-b a \frac{\dot{\alpha}}{V}+\alpha\right)\right. \\
& \left.\left(\left(\frac{\dot{h}}{V}-b a \frac{\dot{\alpha}}{V}+\alpha\right)^{2}+3 \tau^{2}+\left(b \frac{\dot{\alpha}}{V}\right)^{2}\right)\right\}
\end{aligned}
$$

Note that $L_{1}(t), L_{2}(t)$, and $L_{3}(t)$ represent the first, second, and third-order piston theory lift components, respectively. The unsteady moment is represented in a similar manner

$$
M_{E A}(t)=M_{1}(t)+M_{2}(t)+M_{3}(t)
$$

where

$$
\begin{gathered}
M_{1}(t)=4 p_{\infty} \gamma M b^{2}\left\{a \frac{\dot{h}}{V}-\left(\frac{b}{3}+b a^{2}\right) \frac{\dot{\alpha}}{V}+a \alpha\right\} \\
M_{2}(t)=p_{\infty} \gamma(\gamma+1) M^{2} b^{2} \tau\left\{\frac{\dot{h}}{V}-2 b a \frac{\dot{\alpha}}{V}+\alpha\right\} \\
M_{3}(t)=-\frac{1}{3} p_{\infty} \gamma(\gamma+1) M^{3} b^{2}\left\{\frac{1}{5}\left(b \frac{\dot{\alpha}}{V}\right)^{3}\right. \\
-a\left(\frac{\dot{h}}{V}-b a \frac{\dot{\alpha}}{V}+\alpha\right)\left(\left(\frac{\dot{h}}{V}-b a \frac{\dot{\alpha}}{V}+\alpha\right)^{2}+3 \tau^{2}\right) \\
+b \frac{\dot{\alpha}}{V}\left(\left(\frac{\dot{h}}{V}-b a \frac{\dot{\alpha}}{V}+\alpha\right)^{2}+\tau^{2}\right. \\
\left.\left.\quad-b a \frac{\dot{\alpha}}{V}\left(\frac{\dot{h}}{V}-b a \frac{\dot{\alpha}}{V}+\alpha\right)\right)\right\}
\end{gathered}
$$

It is interesting to note that the second-order lift and moment are linear in terms of the displacement variables due to vertical symmetry of the doublewedge airfoil.

For compatibility with CFL3D, it is important to represent Eq. (8) in terms generalized coordinates and forces. This is accomplished by the normal mode transformation given by

$$
\left\{\begin{array}{l}
h(t) \\
\alpha(t)
\end{array}\right\}=[\mathbf{\Phi}]\left\{\begin{array}{l}
q_{1}(t) \\
q_{2}(t)
\end{array}\right\}
$$

Applying the normal mode transformation on the equations of motion, Eq. 8, yields

$$
\begin{aligned}
\left\{\begin{array}{c}
\ddot{q}_{1}(t) \\
\ddot{q}_{2}(t)
\end{array}\right\}=[\boldsymbol{\Phi}]^{T}\left\{\begin{array}{c}
-L(t) \\
M_{E A}(t)
\end{array}\right\} \\
-\left[\begin{array}{cc}
\omega_{1}^{2} & 0 \\
0 & \omega_{2}^{2}
\end{array}\right]\left\{\begin{array}{l}
q_{1}(t) \\
q_{2}(t)
\end{array}\right\}
\end{aligned}
$$

for mass normalized modes. The modal degrees of freedom are coupled through the generalized aerodynamic loads. Equation (18) was solved using the subroutine ODE45 in MATLABC.

\section{Calculation of Effective Shape of the Double-Wedge AIRFoIL}

The thick boundary layer in hypersonic flow displaces the outer inviscid flow, causing a given body shape to appear much thicker. ${ }^{30}$ This influences both the surface pressure distribution and the vehicle aeroelastic stability. This effect can be incorporated in an approximate manner by using a static boundary layer displacement thickness in conjunction with piston theory. A similar approach was considered in Ref. 8, where a flat-plate boundary layer thickness was used. In the present study, the accuracy in calculating the displacement thickness is improved by using the steady pressure distribution obtained from the CFD based Navier-Stokes solution. This displacement thickness is used to determine the modified airfoil shape. The steady component of the piston theory pressure can be obtained from Eq.(7) when all time dependent terms are neglected. For zero angle of attack, this is given by:

$$
\begin{aligned}
C_{p P T}(x)= & \frac{p_{\infty}}{q_{\infty}}\left\{\gamma M \frac{d Z_{\text {eff }}}{d x}+\frac{\gamma(\gamma+1)}{4} M^{2}\left(\frac{d Z_{\text {eff }}}{d x}\right)^{2}\right. \\
& \left.+\frac{\gamma(\gamma+1)}{12} M^{3}\left(\frac{d Z_{\text {eff }}}{d x}\right)^{3}\right\}
\end{aligned}
$$

Equating the steady CFD Navier-Stokes coefficient of pressure with Eq.(19) yields a third order polynomial for $\frac{d Z_{e f f}}{d x}$,

$$
C_{p P T}(x)-C_{p N S}(x)=0
$$

Solving this equation at each surface grid point results in two complex roots, and one real root which represents the slope of the effective airfoil shape at that grid point. The complete effective shape, $Z_{e f f}(x)$, can then be obtained from this slope, $\frac{d Z_{\text {eff }}}{d x}$, by integrating along the length of the airfoil, and assuming zero displacement thickness at the leading edge, i.e. $Z_{\text {eff }}(-b)=0$.

\section{REsults AND Discussion}

The results presented in this section provide a partial validation of CFL3D for the hypersonic regime, and also contribute to the fundamental understanding 
of hypersonic aeroelasticity. By comparing results for Euler, Navier-Stokes and piston theory, one can identify the importance of viscosity, and the effectiveness of piston theory in approximating the aeroelastic behavior of a double-wedge airfoil in inviscid flow.

The present study utilizes two different configurations, one of which was selected based on engineering judgment, and a second motivated by the desire to deal with a specific configuration that has flown at high speeds. The second configuration resembles a Lockheed F-104 Starfighter wing crosssection at $75 \%$ of span, and is assumed to be made of 2024-T3 Aluminum alloy. These are referred to as Configuration I and Configuration II, respectively. Additional parameters for both configurations of the double-wedge airfoil are given in Table 2. Using two different configurations extends the parameter range covered by the results, and this gives a more comprehensive view of aeroelastic behavior in the hypersonic regime.

\section{Selection of Time-step Size}

The time-step required for accurate prediction of the aeroelastic response is important in computational aeroelasticity studies. However, selection of small time-steps also requires significant computational resources. The optimal time-step is determined by a trade-off between accuracy and demands on computational resources. This was established by a concise numerical study.

In an aeroelastic system with a linear structural operator, the time-step limitation is governed by the unsteady fluid calculations. A simulation based on prescribed motion of the geometry in Configuration I was used to select an appropriate timestep size for each of the flight conditions. To determine the proper step size, the unsteady lift, moment and drag coefficients $\left(C_{L}(t), C_{M y}(t)\right.$ and $\left.C_{D}(t)\right)$, due to prescribed motion were computed, and the time-step selected was based on the convergence of these unsteady aerodynamic coefficients. It was found that the lift coefficient $C_{L}$ has the smallest degree of sensitivity to the time-step selection. For aeroelastic simulations, the lift is the dominant quantity since drag does not appear in the aeroelastic calculations for the double-wedge airfoil. For the double-wedge airfoil geometry, the moment due to lift $\left(C_{L} \cdot a\right)$ has the same order of magnitude as the moment coefficient, and hence the accuracy of $C_{M y}$ is comparable in importance to the accuracy in $C_{L}$. Therefore one may be tempted to determine the accuracy requirement primarily from the behavior of the unsteady lift.
For simulations using Euler aerodynamics, the responses were found to be independent of timestep size when the time-step was smaller than 0.001 sec. To identify the maximum time-step for a viscous simulation, a maximum time-step for a viscous forced-motion simulation was found. This value determined the upper limit for the time-step size used in the aeroelastic simulations. Simulations were carried out at 10,20 and $30 \mathrm{~Hz}$, with a maximum rotation of $1^{\circ}$ and $2^{\circ}$, at various altitudes. Results from simulations carried out at 70,000 feet and Mach 10, with maximum rotation of $2^{\circ}$ at $20 \mathrm{~Hz}$, are shown in Fig.5. In an aeroelastic simulation, the phase difference between the oscillations in $C_{L}(t)$ and $C_{M y}(t)$ plays a very important role in the stability of the system. A phase difference in the oscillations in $C_{L}(t), C_{M y}(t)$ and $C_{D}(t)$ in a forced-motion simulation would lead to incorrect aeroelastic behavior at those flight conditions. Hence, when viscosity is considered, $C_{D}$ is a better indicator of convergence than $C_{L}$, even though $C_{D}$ plays no role in this particular aeroelastic problem. This is because $C_{D}$ is the best indicator of a phase difference between the various coefficients in a prescribed motion simulation. It was found that the errors in magnitude and phase were not strongly affected by the frequency or magnitude of the oscillations at a given altitude. The results of this study are summarized in Table 3. Since aeroelastic simulations tend to be sensitive to small errors in phase, these results were also verified by carrying out aeroelastic simulations with the different time-step sizes.

The simulations in this study were carried out in sequential mode on individual nodes of a SGI Origin 2000 parallel computer with R10000 processors. Based on the time-step sizes indicated in Table 3, the run time for an aeroelastic simulation of the double-wedge airfoil using Euler aerodynamics is approximately 10 hours, and approximately 110 hours when using Navier-Stokes aerodynamics. The significant increase in computational resources for viscous aeroelasticity is a reflection of the more complex aerodynamic equations as well as the smaller time-step size and increased subiterations required.

\section{Aeroelastic Behavior of the} DOUBLE-WEDGE AIRFOIL

Figure 6 depicts the flutter boundaries of Configuration I at various altitudes, as a function of the offset $a$, for the operating envelope of a typical hypersonic vehicle, at $0^{\circ}$ angle of attack, based on third-order piston theory. The mass ratios for the various altitudes, calculated using the standard 
atmosphere, are given in Table 1. For the Mach number range of $5<M<15$, the height selected for the flutter calculations of this configuration was 70,000 feet. At this altitude, the flutter boundaries are at $M_{f}=9.21$ for $a=0.1$ and at $M_{f}=14.96$ for $a=-0.2$. Sample computational points from this study were Mach numbers 7, 10 and 15 at 70,000 feet, with Reynolds numbers of $3.336 \times 10^{6}$, $4.766 \times 10^{6}$ and $7.149 \times 10^{6}$, respectively.

The results for the aeroelastic behavior of Configuration I with $a=0.1$ using different aerodynamic models is shown in Fig. 7. The linear nature of the second-order piston theory model allowed an eigenanalysis for comparison with frequency and damping characteristics from second-order piston theory aeroelastic transients. From this figure, the flutter Mach number predicted by second-order piston theory was $M_{f}=9.79$. In general, results from the time history analysis agreed with the eigenanalysis. The sharp coalesce shown in Fig. 7 is due to an inability of the moving block approach to distinguish between the damping and frequency characteristics of the transient motion as the flutter Mach number is approached and the two modes begin to interact. The flutter Mach number obtained with Euler aerodynamics is $M_{f}=6.75$, and when NavierStokes aerodynamics is used, flutter is found to be at $M_{f}=6.59$.

For Configuration I with $a=-0.2$, Fig. 8 indicates that differences in system response from the three aerodynamic models are minor at Mach numbers well below the flutter boundaries. However, these differences increase with Mach number. An eigenanalysis using second-order piston theory indicates flutter at $M_{f}=15.16$, while an analysis of third-order piston theory aeroelastic transients indicates flutter at $M_{f}=14.96$. It is apparent that, for this configuration, third-order piston theory is slightly more conservative than second-order piston theory. With Euler aerodynamics, the flutter boundary drops to $M_{f}=11.76$, and using NavierStokes aerodynamics results in a further reduction to $M_{f}=11.15$. These differences emphasize the importance of aerodynamic nonlinearities and viscosity with increasing Mach numbers.

The effect of the wedge angle (or thickness) of the airfoil is depicted in Fig. 9, at 70,000 feet. Increasing the wedge angle to $4^{\circ}$, for Configuration I with $a=-0.2$, reduces the flutter Mach numbers predicted by all three models. Third-order piston theory yields $M_{f}=12.56$, using Euler aerodynamics reduces the flutter boundary to $M_{f}=10.54$ and Navier-Stokes aerodynamics results in a further reduction of the flutter boundary to $M_{f}=9.59$.
All the cases considered were at $0^{\circ}$ static angle of attack. Hypersonic vehicles in trimmed flight will operate at an angle of attack. The effect of static angle of attack on the aeroelastic behavior of Configuration I with $a=-0.2$ is considered next. Figure 10 shows the aeroelastic behavior of the double-wedge airfoil using third-order piston theory, for static angles of attack given by $\alpha_{s}=0^{\circ}, 1^{\circ}$ and $2^{\circ}$. Increasing the static angle of attack reduces the flutter boundary proportionally by a small value. Similar behavior is obtained when using Euler aerodynamics, shown in Fig. 11, and also when using Navier-Stokes aerodynamics, as shown in Fig. 12. These results indicate that having a small static angle of attack does not significantly affect the flutter behavior of the double-wedge airfoil. For the sake of completeness, these results are also summarized in Table 4.

The effective shape modification due to the presence of the boundary layer at Mach 7.0, 10.0 and 15.0 for Configuration I, are shown in Fig. 13. The effective geometries are calculated from steady CFD Navier-Stokes pressure data, as described previously. Figure 14 presents a comparison of the aeroelastic stability boundaries at 70,000 feet using the modified shape, as well as Euler and Navier-Stokes based unsteady loads. When the effective shape is used in conjunction with piston theory aerodynamics, flutter is predicted at $M_{f}=13.31$ which is significantly higher than the value of $M_{f}=11.15$ predicted by Navier-Stokes aerodynamics. The limited number of results presented for the approximate approach based on using piston theory with a modified airfoil shape is insufficient to determine whether this is a reliable approximation.

Figure 15 shows the flutter boundaries of Configuration II at 40,000 feet and 70,000 feet, in comparison with the flutter boundaries of Configuration I at the same altitudes, calculated using third-order piston theory. The flutter boundaries, at corresponding altitudes, of Configuration II are significantly higher than for Configuration I, due to a stiffer wing structure. For the Mach number range of $5<M<15$, the height selected for flutter calculations of Configuration II was 40,000 feet. Some computational points selected for this altitude were Mach numbers 7, 10 and 15, which correspond to Reynolds' numbers of $1.378 \times 10^{7}, 1.969 \times 10^{7}$ and $2.954 \times 10^{7}$, respectively.

The aeroelastic behavior of Configuration II with $a=0.1$, obtained using different aerodynamic models, is shown in Fig. 16. Use of piston theory yields flutter at $M_{f}=12.01$, while the Euler loads reduce the boundary to $M_{f}=9.39$, and the Navier- 
Stokes based loads result in a relatively minor reduction to $M_{f}=8.97$. Modifying the offset to $a=-0.2$ changes the flutter boundary to $M_{f}=16.67$, 13.76 and 13.30 when using piston theory, Euler and Navier-Stokes models, respectively, as shown in Fig. 17.

\section{Aerothermoelastic Behavior of THE} DOUBLE-WEDGE AIRFOIL

Configuration II represents a configuration where the effects of aerodynamic heating are ignored. A realistic model for the hypersonic regime must include aerodynamic heating effects. Aerodynamic heating significantly alters the flow properties, ${ }^{31}$ degrades the material properties and also introduces thermal stresses. ${ }^{32-34}$ Aerodynamic heating of the surrounding airflow leads to significantly different thermodynamic and transport properties, high heattransfer rates, variable $\gamma$, possible ionization, and nonadiabatic effects from radiation. ${ }^{31,32}$ Thermal stresses arise from rapidly changing conditions of heat input where time lags are involved, or also from equilibrium conditions of non-uniform temperature distribution. ${ }^{33,34}$ Commonly, the heated structure has lowered stiffness due to material degradation and thermal stresses, which manifests itself as a lowering of the natural frequencies. ${ }^{33-35}$

An accurate treatment of aerothermoelasticity may require the coupling of the unsteady heat transfer problem with the aeroelastic problem based on the Navier-Stokes solution of the unsteady airloads. Instead of dealing with this complicated problem, the results presented here are intended to explore the basic aspect of temperature change so as to gain an approximate measure for the importance of this effect. These approximate calculations are carried out by considering the effect of elevated temperatures on the structural stiffness and associated frequencies.

As a first approximation of the effects of aerodynamic heating, the changes in model stiffness associated with degradation of the modulus of elasticity are considered. When a metal is heated above room temperature, its modulus begins to decrease gradually, and the process accelerates as higher temperatures are reached. Experimental measurements indicate that the modulus of elasticity decreases more rapidly for static measurements when compared to dynamic measurements. ${ }^{34}$ Reference 36 indicates that this difference is due to several internal-friction mechanisms, among which anelastic effects appear to be predominant. Data on the dynamic modulus of elasticity for various alloys, including 2024-T3 Aluminum alloy used in the present study, at differ- ent temperatures are also provided.

The simple model considered assumes the existence of an efficient thermal protection system designed to provide a linear increase in temperature from $200^{\circ} \mathrm{F}$ at $M=3.5$ to $350^{\circ} \mathrm{F}$ at $M=10.0$. Beyond $M=10.0$, the thermal protection system loses its efficiency and the temperature increases such that it is proportional to the adiabatic wall temperature, reaching a temperature of $1000^{\circ} \mathrm{F}$ at $M=20.0$. This variation is given by,

$$
\begin{aligned}
T=f_{1}(M) & =200+23.1(M-3.5) & & 2 \leq M \leq 10 \\
& =318.1+4.2(M-7.2)^{2} & & 10<M \leq 20
\end{aligned}
$$

and is shown in Fig. 18(a). The corresponding variation of the dynamic modulus of elasticity with Mach number is shown in Fig.18(b).

Using this temperature distribution, piston theory was used to calculate the flutter boundary for Configuration II for a variety of offsets, and this was compared with flutter boundaries obtained by heating the wing uniformly to temperatures of $200^{\circ} \mathrm{F}, 500^{\circ} \mathrm{F}$, and $800^{\circ} \mathrm{F}$, as shown in Fig.19. It is apparent that heating the wing to a constant temperature results in an almost uniform reduction in aeroelastic stability for all variations in $a$. However, varying temperature with Mach number results in a nonuniform reduction in aeroelastic stability, where the reduction is dependent on $a$. As the elastic axis is moved from $a=-0.4$ to $a=0.4$, the reduction in aeroelastic stability due to aerodynamic heating decreases. When the the elastic axis is moved aft, the Mach numbers required to initiate flutter decrease. This implies the wing is heated to a lower temperature, and therefore experiences a smaller reduction in stiffness. In all cases, the flutter Mach number decreases with increasing temperature. The aeroelastic behavior of the heated wing with $a=0.1$ is shown in Fig. 20, while the behavior obtained using $a=-0.2$ is shown in Fig. 21. Both figures show that there is a decrease in $M_{f}$ when compared to the wing in the absence of aerodynamic heating. Figure 22 shows the flutter boundaries calculated using the different aerodynamic methods for the unheated and the heated wings. These results imply that similar trends in the flutter boundary are evident, irrespective of the method used to calculate the unsteady aerodynamic loads.

Aeroelastic Behavior of a Generic Reusable Launch Vehicle

The model employed is based on a generic vehicle 
that resembles a lifting body that can be used in the design of a reusable launch vehicle. The model represents only the fuselage of the vehicle. A coarsened view of the computational domain is shown in Fig. 23. The dimensions of the generic vehicle are $76.2 \mathrm{ft}$. length, $45.54 \mathrm{ft}$. width and $6 \mathrm{ft}$. thickness. The empty mass of the vehicle is considered to be 70,000 lbs. From these specifications, the unrestrained modes were obtained. The model is currently being extended to include lifting surfaces. Currently, aeroelastic calculations using Euler and Navier-Stokes based unsteady aerodynamic loads are being carried out, so as to determine the effect of viscosity on the aeroelastic stability boundaries. Results for the generic hypersonic vehicle will constitute an important contribution to the state of the art. The run time for an aeroelastic simulation using Euler aerodynamics is approximately 60 hours on individual processors of a SGI Origin 2000, which increases to 700 hours when using Navier-Stokes aerodynamics.

\section{$\underline{\text { CONCLUSIONS }}$}

Based on the numerical results presented in this paper, the following conclusions can be stated.

1. The time steps to be used in computational aeroelasticity studies are strongly dependent on the unsteady aerodynamic model used. Using a viscous flow based on the Navier-Stokes equations requires time-step sizes at least an order of magnitude smaller than those used for an Euler solution, when using the same number of subiterations.

2. At subcritical Mach numbers, aeroelastic behavior predicted using the various models is fairly close. The frequency and damping characteristics are comparable. These differences increase substantially at, and beyond, the stability boundary.

3. Stability boundaries predicted by Euler solutions are approximately 20-25\% lower than those predicted by piston theory. The NavierStokes solutions are approximately $5 \%$ further below Euler.

4. The various aeroelastic models predict similar trends due to changes in parameters such as: offset between the elastic axis and midchord, wedge angle and static angle of attack for the double-wedge airfoil.
5. Airfoil shapes modified by the presence of a static boundary layer predicts flutter at a Mach number $20 \%$ higher than that obtained using the the Navier-Stokes equations. However, the general validity of this approach is questionable.

6. Material property degradation due to aerodynamic heating can reduce the aeroelastic stability of the double-wedge airfoil significantly. For the assumed temperature variation, reductions in the range of $5 \%-15 \%$ were observed.

7. The results presented can be considered to provide a partial validation of the aeroelastic capabilities of the CFL3D code for the hypersonic flow regime.

\section{$\underline{\text { ACKNOWLEDGMENT }}$}

The authors wish to express their gratitude to NASA Langley Research Center for the CFL3D code and thank Drs. R. Bartels and R. Biedron for their help in using this code. This research has benefited from partial support from several sources, AFOSR grant F49620-01-0158 with Dr. D. Mook as program manager, NASA Dryden training grant NGT4-52426 (to J. McNamara) and NASA URETI award NCC 3989 funded by NASA Marshall and Glenn Research Centers.

\section{$\underline{\text { REFERENCES }}$}

[1] Xue, D.Y. and Mei, C., "Finite Element Two-Dimensional Panel Flutter at High Supersonic Speeds and Elevated Temperature," AIAA Paper No. 90-0982, Proc. 31st AIAA/ASME/ASCE/AHS/ASC Structures, Structural Dynamics and Materials Conference, 1990, pp. 1464-1475.

[2] Gray, E.G. and Mei, C., "Large-Amplitude Finite Element Flutter Analysis of Composite Panels in Hypersonic Flow," AIAA Paper No. 92-2130, Proc. 33rd AIAA/ASME/ASCE/AHS/ASC Structures, Structural Dynamics and Materials Conference, Dallas, TX, April 16-17 1992, pp. 492-512.

[3] Abbas, J.F. and Ibrahim,R.A., "Nonlinear Flutter of Orthotropic Composite Panel Under Aerodynamic Heating," AIAA J., Vol. 31, No. 8 , No. 8,1993 , pp. $1478-1488$. 
[4] Bein, T., Friedmann, P., Zhong, X., and Nydick, I., "Hypersonic Flutter of a Curved Shallow Panel with Aerodynamic Heating," AIAA Paper No. 93-1318, Proc. 34th AIAA/ASME/ASCE/AHS/ASC Structures, Structural Dynamics and Materials Conference, La Jolla, CA, April 19-22 1993.

[5] Nydick, I., Friedmann, P.P., and Zhong, X., "Hypersonic Panel Flutter Studies on Curved Panels," AIAA Paper no. 95-1485, Proc. 36th AIAA/ASME/ASCE/AHS/ASC Structures, Structural Dynamics and Materials Conference, New Orleans, LA, April 1995, pp. 2995-3011.

[6] Mei, C., Abdel-Motagly, K., and Chen, R., "Review of Nonlinear Panel Flutter at Supersonic and Hypersonic Speeds," Applied Mechanics Reviews, 1998.

[7] Ricketts, R., Noll, T., Whitlow, W., and Huttsell,L., "An Overview of Aeroelasticity Studies for the National Aerospace Plane," AIAA Paper No. 93-1313, Proc. 34th AIAA/ASME/ASCE/AHS/ASC Structures, Structural Dynamics and Materials Conference, La Jolla, CA, April 19-22 1993, pp. 152 162.

[8] Spain, C., Zeiler, T.A., Bullock, E., and Hodge, J.S., "A Flutter Investigation of AllMoveable NASP-Like Wings at Hypersonic Speeds," AIAA Paper No. 93-1315, Proc. 34th AIAA/ASME/ASCE/AHS/ ASC Structures, Structural Dynamics and Materials Conference, La Jolla, CA, April 19-22 1993.

[9] Scott, R.C. and Pototzky, A.S., "A Method of Predicting Quasi-Steady Aerodynamics for Flutter Analysis of High Speed Vehicles Using Steady CFD Calculations," AIAA Paper No. 93-1364, Proc. 34th AIAA/ASME/ASCE/AHS/ASC Structures, Structural Dynamics and Materials Conference, La Jolla, CA, April 19-22 1993, pp. 595-603.

[10] Spain, C., Zeiler, T.A., Gibbons, M.D., Soistmann, D.L., Pozefsky, P., DeJesus, R.O., and Brannon,C.P., "Aeroelastic Character of a National Aerospace Plane Demonstrator Concept," Proc. 34th AIAA/ASME/ASCE/AHS/ $A S C$ Structures, Structural Dynamics and $M a-$ terials Conference, La Jolla, CA, April 19-22 1993, pp. 163-170.
[11] Rodgers, J.P., "Aerothermoelastic Analysis of a NASP-Like Vertical Fin," AIAA-92-2400-CP, Proc. 33rd AIAA/ASME/ASCE/AHS Structures, Structural Dynamics and Materials Conference, Dallas, TX, April 1992.

[12] Heeg, J., Zeiler, T., Pototzky, A., Spain, C., and Engelund, W., "Aerothermoelastic Analysis of a NASP Demonstrator Model," AIAA Paper No. 93-1366, Proc. 34th AIAA/ASME/ASCE/AHS/ ASC Structures, Structural Dynamics and Materials Conference, La Jolla, CA, April 19-22 1993, pp. 617-627.

[13] Heeg, J. and Gilbert, M.G., "Active Control of Aerothermoelastic Effects for a Conceptual Hypersonic Aircraft," Journal of Aircraft, Vol. 30, 1993, pp. 453-458.

[14] Blades, E., Ruth, M., and Fuhrman, D., "Aeroelastic Analysis of the X-34 Launch Vehicle," AIAA Paper No. 99-1352, Proc. 40th AIAA/ASME/ASCE/AHS/ ASC Structures, Structural Dynamics and Materials Conference, St. Louis, MO, 1999, pp. 1321-1331.

[15] Nydick, I. and Friedmann, P.P., "Aeroelastic Analysis of a Generic Hypersonic Vehicle," NASA/CP-1999-209136/PT2, Proc. CEAS/AIAA/ICASE/NASA Langley International Forum on Aeroelasticity and Structural Dynamics, Williamsburg, VA, June 22-25 1999, pp. $777-810$.

[16] Gupta, K.K., Voelker, L.S., Bach, C., Doyle, T., and Hahn, E., "CFD-Based Aeroelastic Analysis of the X-43 Hypersonic Flight Vehicle," AIAA Paper No. 2001-0712, 39th Aerospace Sciences Meeting \& Exhibit, 2001.

[17] Berry, S.A., Horvath, T.J., Hollis, B.R., Thompson, R.A., and Hamilton, H.H., "X-33 Hypersonic Boundary Layer Transition," AIAA Paper No. 99-3560, 33rd AIAA Thermophysics Conference, Norfolk, VA, June 28 - July 11999.

[18] Riley, C.J., Kleb, W.L., and Alter, S.J., "Aeroheating Predictions for X-34 Using An InviscidBoundary Layer Method," AIAA 98-0880, 36th Aerospace Sciences Meeting \& Exhibit, Reno, NV, January 1998.

[19] Thuruthimattam, B.J., Friedmann, P.P., McNamara, J.J., and Powell, K.G., "Aeroelasticity of a Generic Hypersonic Vehicle," AIAA Paper No. 2002-1209, Proc. 43rd 
AIAA/ASME/ASCE/AHS Structures, Structural Dynamics and Materials Conference, Denver, CO, April 2002.

[20] Krist, S.L., Biedron, R.T., and Rumsey, C.L., "CFL3D User's Manual (Version 5.0)," NASA, TM 1998-208444, 1997.

[21] Robinson, B.A., Batina, J.T., and Yang, H.T., "Aeroelastic Analysis of Wings Using the Euler Equations with a Deforming Mesh," Journal of Aircraft, Vol. 28, November 1991, pp. 778-788.

[22] Cunningham, H.J., Batina, J.T., and Bennett, R.M., "Modern Wing Flutter Analysis by Computational Fluid Dynamic Methods," Journal of Aircraft, Vol. 25, No. 10, No. 10, 1989, pp. $962-968$.

[23] Lee-Rausch, E.M. and Batina, J.T., "Wing Flutter Boundary Prediction Using Unsteady Euler Aerodynamic Method," AIAA Paper No. 93-1422, Proc. 34th AIAA/ASME/ASCE/AHS Structures, Structural Dynamics and Materials Conference, 1993, pp. 1019-1029.

[24] Lee-Rausch, E.M. and Batina, J.T., "Calculation of AGARD Wing 445.6 Flutter Using Navier-Stokes Aerodynamics," AIAA Paper No. 93-3476, Proc. AIAA 11th Applied Aerodynamics Conference, Hampton, VA, August 9-11 1993.

[25] Bousman, W.G. and Winkler, D.J., "Application of the Moving-Block Analysis," AIAA 810653, Proceedings of the AIAA Dynamics Specialist Conference, Atlanta, GA, April 1981, pp. $755-763$.

[26] Chen, P.C. and Liu, D.D., "Unified Hypersonic/Supersonic Panel Method for Aeroelastic Applications to Arbitrary Bodies," Journal of Aircraft, Vol. 39, No. 3, No. 3, 2002, pp. 499506.

[27] Liu, D.D., Chen, P.C., Tang, L., Chang, K.T., and Gao, X.W., "Expedient Hypersonic Aerothermodynamics Methodology for RLV/TPS Design," Proc. 11th AIAA/AAAF International Conference on Space Planes and Hypersonic Systems and Technologies, Orleans, France, September 2002.

[28] Ashley, H. and Zartarian, G., "Piston Theory - A New Aerodynamic Tool for the Aeroelastician," Journal of the Aeronautical Sciences, Vol. 23, No. 12, No. 12, 1956, pp. 1109-1118.
[29] Lighthill, M.J., "Oscillating Airfoils at High Mach Numbers," Journal of the Aeronautical Sciences, Vol. 20, No. 6, June 1953.

[30] Anderson, J.D., Hypersonic and High Temperature Gas Dynamics, New York, McGraw-Hill, 1989.

[31] Anderson, J.D., Aerothermodynamics: A Tutorial Discussion in Thermal Structures and $M a-$ terials for High-speed Flight, AIAA, 1992, Ch. 1, pp. $3-57$.

[32] Bisplinghoff, R.L., "Some Structural and Aeroelastic Considerations of High-Speed Flight," Journal of the Aerospace Sciences, Vol. 23, No. 4, April 1956, pp. 289-329.

[33] Rogers, M., "Aerothermoelasticity," AeroSpace Engineering, October 1958, pp. 34-43.

[34] Garrick, I.E., "Aeroelasticity Effects of High Temperatures," Aerospace Engineering, January 1963, pp. $140-147$.

[35] Budiansky, B. and Mayers, J., "Influence of Aerodynamic Heating on the Effective Torsional Stiffness of Thin Wings," Journal of the Aeronautical Sciences, December 1956, pp. 1081-1093.

[36] Vosteen, L.F., "Effect of Temperature on Dynamic Modulus of Elasticity of Some Structural Alloys," NACA, TN 4348, August 1958.

Table 1: Mass Ratio at at various altitudes.

\begin{tabular}{|c|c|c|}
\hline $\begin{array}{c}\text { Altitude } \\
\text { (feet) }\end{array}$ & $\begin{array}{c}\mu_{m} \\
\text { Configuration I }\end{array}$ & $\begin{array}{c}\mu_{m} \\
\text { Configuration II }\end{array}$ \\
\hline 0 & 13.47 & 24.50 \\
5,000 & 15.63 & 28.43 \\
40,000 & 141.81 & 257.91 \\
70,000 & 232.68 & 423.32 \\
100,000 & 942.60 & - \\
\hline
\end{tabular}


Table 2: Comparison of parameters describing Configurations I and II.

\begin{tabular}{|l|c|c|}
\hline Parameter & Configuration I & Configuration II \\
\hline$c(\mathrm{~m})$ & 2.00 & 2.35 \\
$\begin{array}{l}\text { Thickness } \\
\text { ratio(\%) }\end{array}$ & 2.5 & 3.36 \\
$\begin{array}{l}\text { Wedge } \\
\text { angle }\left(^{\circ}\right)\end{array}$ & 2.86 & 3.85 \\
$m(\mathrm{~kg} / \mathrm{m})$ & 51.8 & 94.2 \\
$r_{\alpha}$ & 0.5 & 0.484 \\
$\omega_{h}(\mathrm{~Hz})$ & 7.96 & 13.4 \\
$\omega_{\alpha}(\mathrm{Hz})$ & 19.9 & 37.6 \\
$\frac{\omega_{h}}{\omega_{\alpha}}$ & 0.4 & 0.356 \\
$x_{\alpha}$ & 0.2 & 0.2 \\
\hline
\end{tabular}

Table 3: Suggested timestep sizes and corresponding number of subiterations for aeroelastic simulations.

\begin{tabular}{|l|c|c|c|}
\hline $\begin{array}{l}\text { Altitude } \\
\text { (feet) }\end{array}$ & Mach no. & $\begin{array}{c}\text { Time-step } \\
(\mathrm{sec})\end{array}$ & $\begin{array}{c}\text { No. of } \\
\text { subiterations }\end{array}$ \\
\hline 50,000 & 5.0 & 0.001 & 10 \\
70,000 & 10.0 & 0.0003 & 40 \\
100,000 & 10.0 & 0.0001 & 40 \\
\hline
\end{tabular}

Table 4: Effect of static angle of attack on flutter Mach number for different aerodynamic models, Configuration I, $a=-0.2$.

\begin{tabular}{|l|c|c|c|}
\hline $\begin{array}{l}\text { Aerodynamic } \\
\text { Model }\end{array}$ & $\begin{array}{c}M_{f} \\
\alpha_{s}=0^{\circ}\end{array}$ & $\begin{array}{c}M_{f} \\
\alpha_{s}=1^{\circ}\end{array}$ & $\begin{array}{c}M_{f} \\
\alpha_{s}=2^{\circ}\end{array}$ \\
\hline $\begin{array}{l}\text { Third-order } \\
\text { piston theory }\end{array}$ & 14.96 & 14.85 & 14.61 \\
Euler & 11.76 & 11.72 & 11.60 \\
Navier-Stokes & 11.15 & 11.08 & 11.01 \\
\hline
\end{tabular}

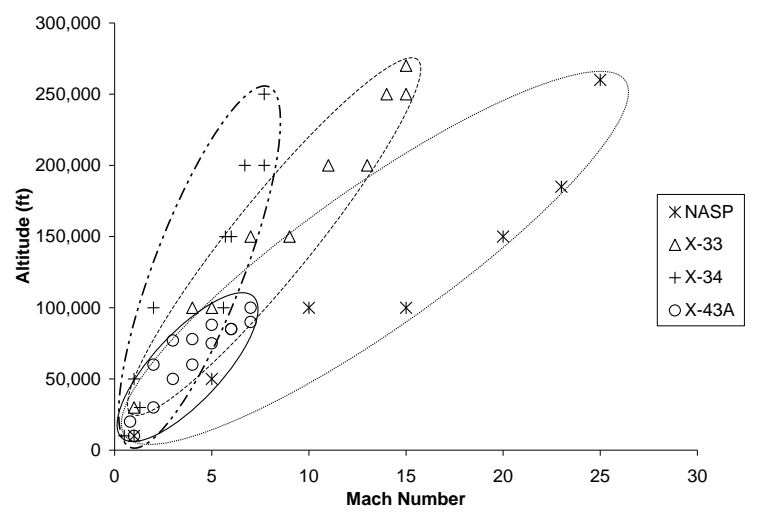

Figure 1: Operating envelopes for several modern hypersonic vehicles.

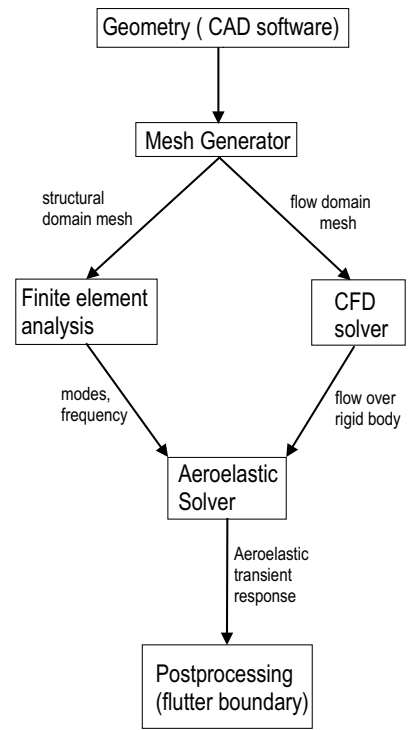

Figure 2: A flow diagram of the computational aeroelastic solution procedure. 


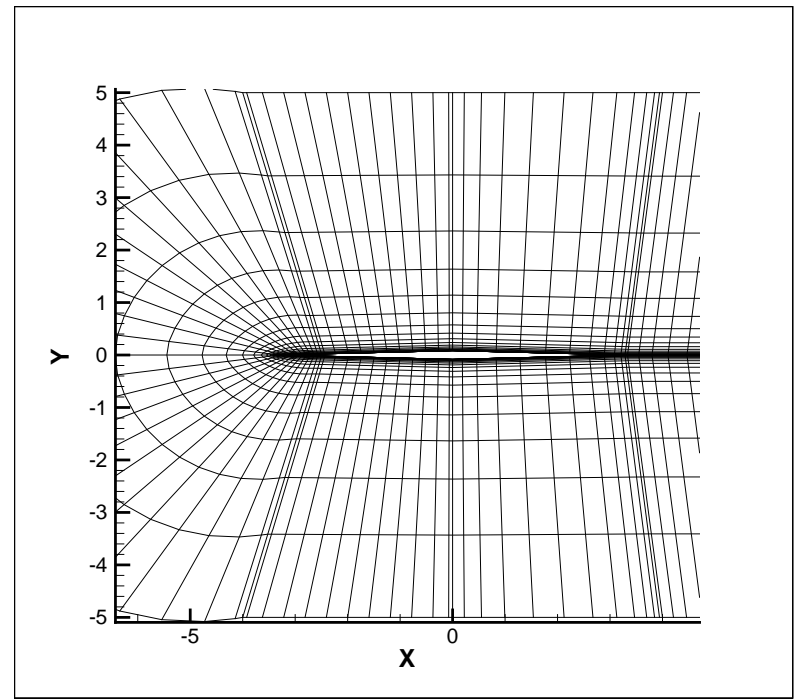

Figure 3: Double-wedge airfoil section, and surrounding grid, to scale, Configuration I.

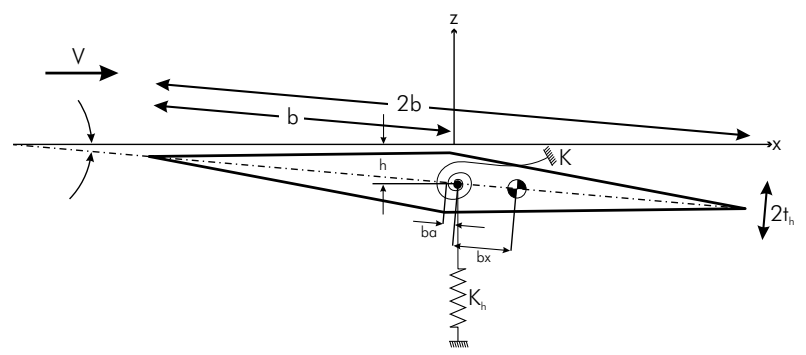

Figure 4: Two degree-of-freedom typical airfoil geometry.
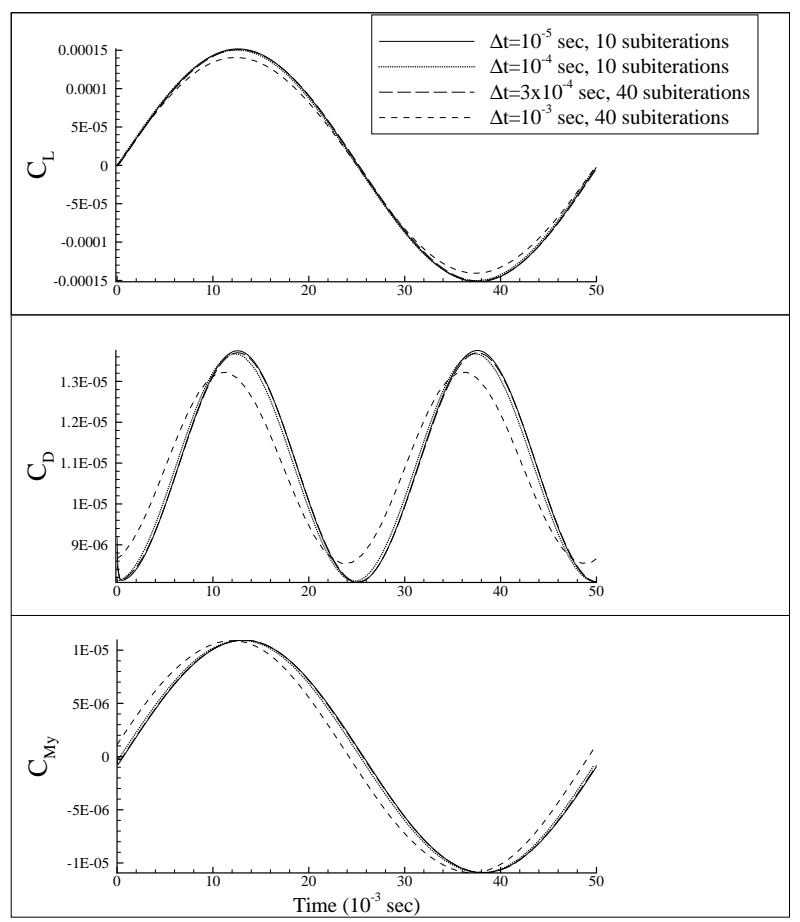

Figure 5: Results for forced pitching motion at Mach 10 and 70,000 feet, with a maximum pitch angle of $2^{\circ}$ at $20 \mathrm{~Hz}$, Configuration I.

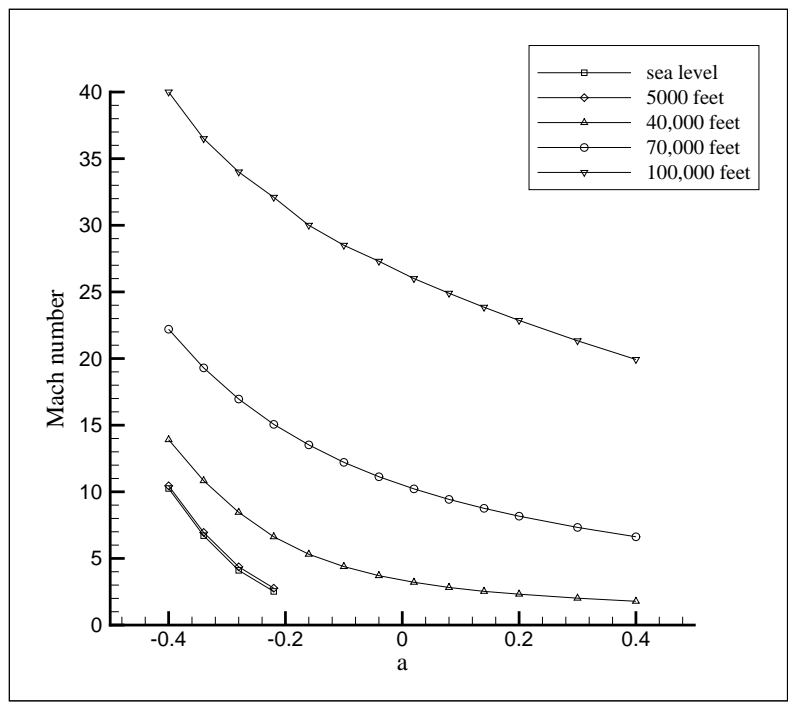

Figure 6: Flutter boundaries of Configuration I at zero angle of attack, obtained using third-order piston theory. 


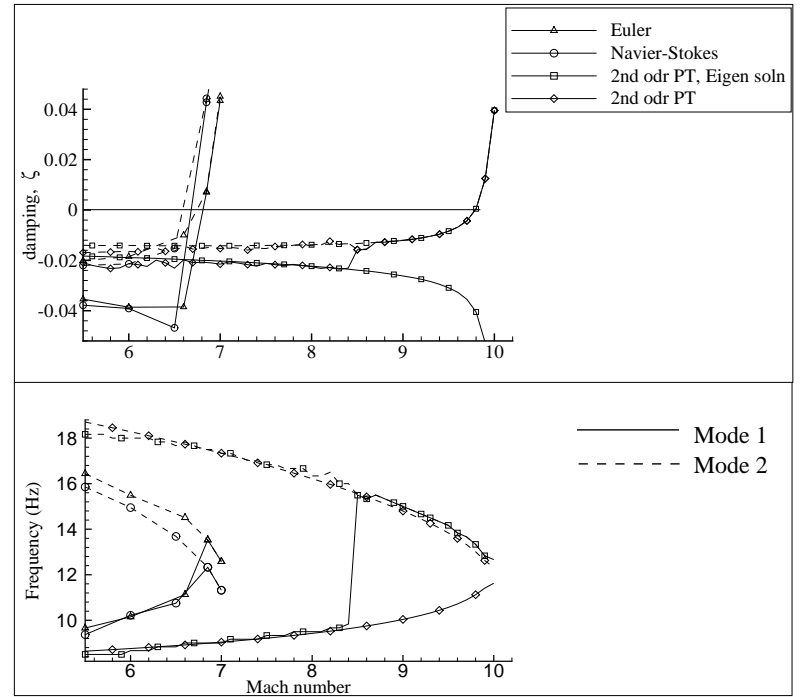

Figure 7: Comparison of aeroelastic results for Configuration I, at an altitude of 70,000 feet, $a=0.1$.

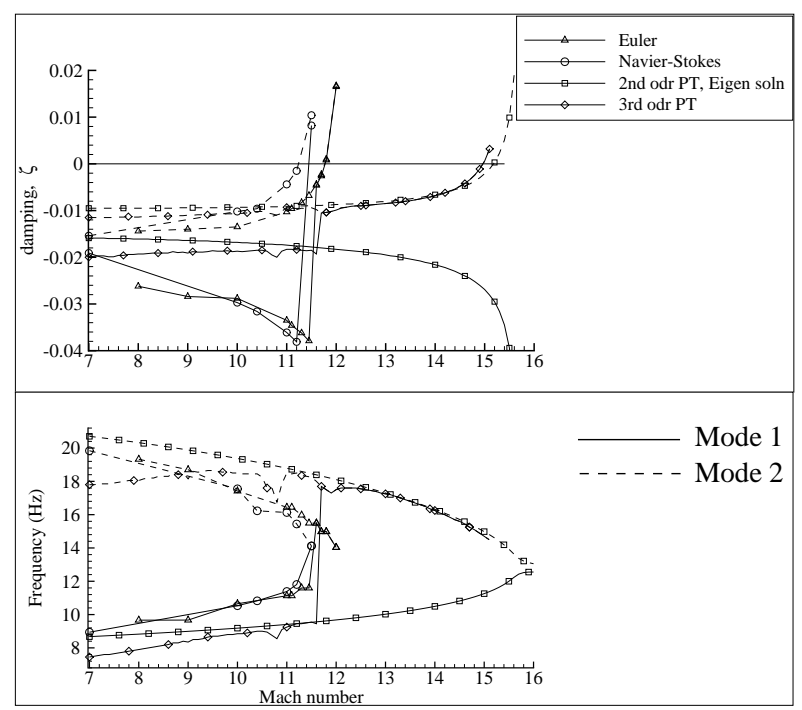

Figure 8: Comparison of aeroelastic results for Configuration I, at an altitude of 70,000 feet, $a=-0.2$.

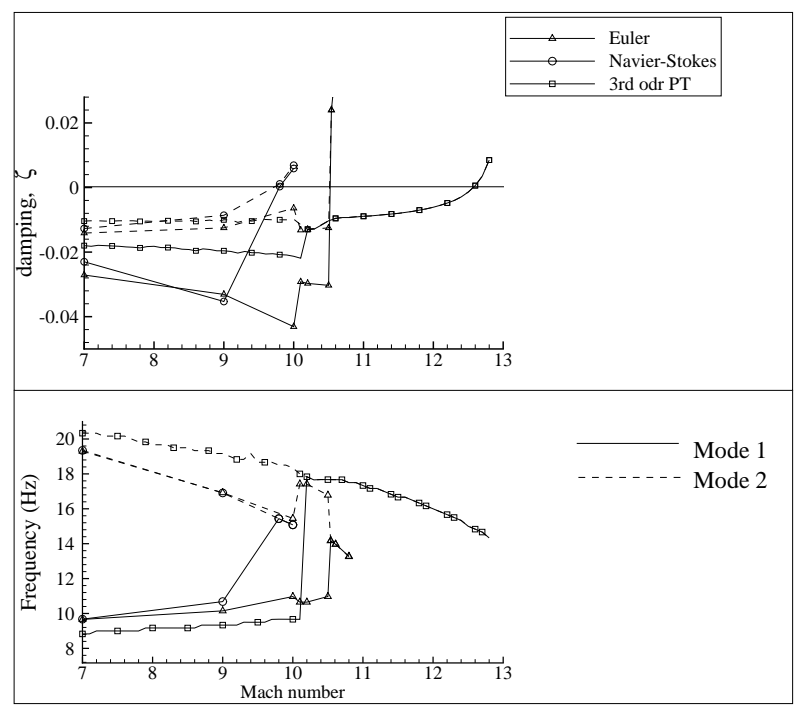

Figure 9: Comparison of aeroelastic results for Configuration I, at an altitude of 70,000 feet, $a=-0.2$, wedge angle $=4^{\circ}$.

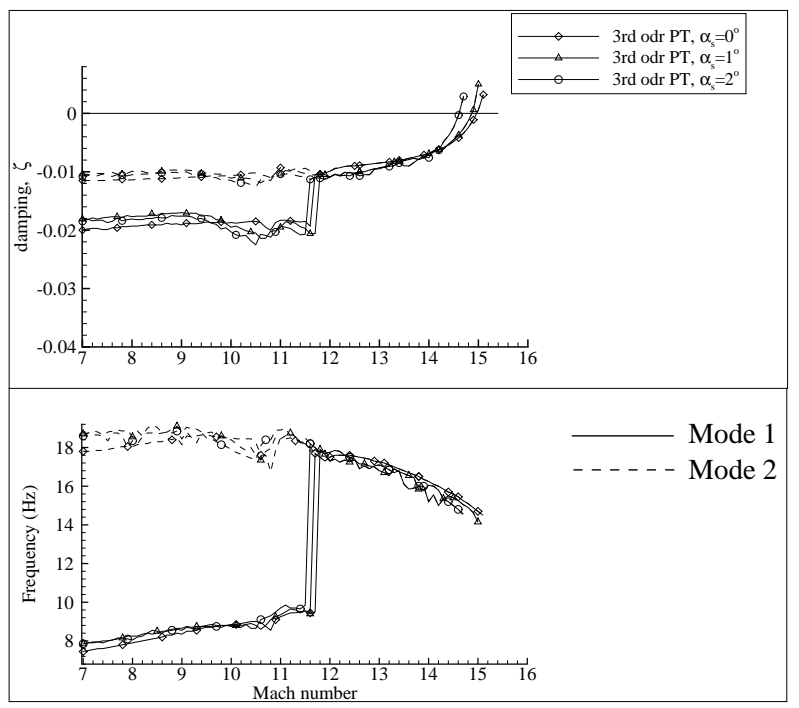

Figure 10: Effect of static angle of attack on the aeroelastic behavior of Configuration I, at an altitude of 70,000 feet, using third-order piston theory, $a=-0.2$. 


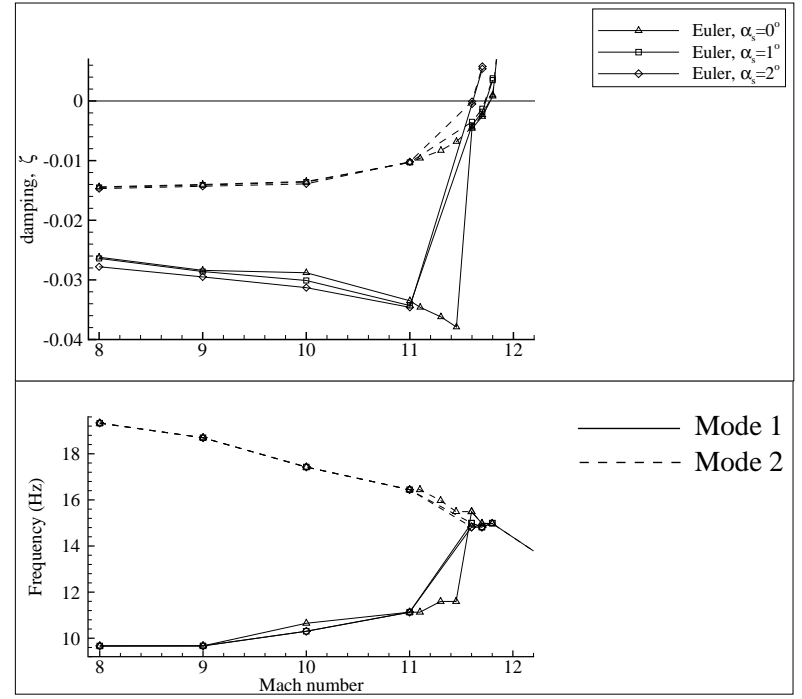

Figure 11: Effect of static angle of attack on the aeroelastic behavior of Configuration I, at an altitude of 70,000 feet, using Euler aerodynamics, $a=-0.2$.

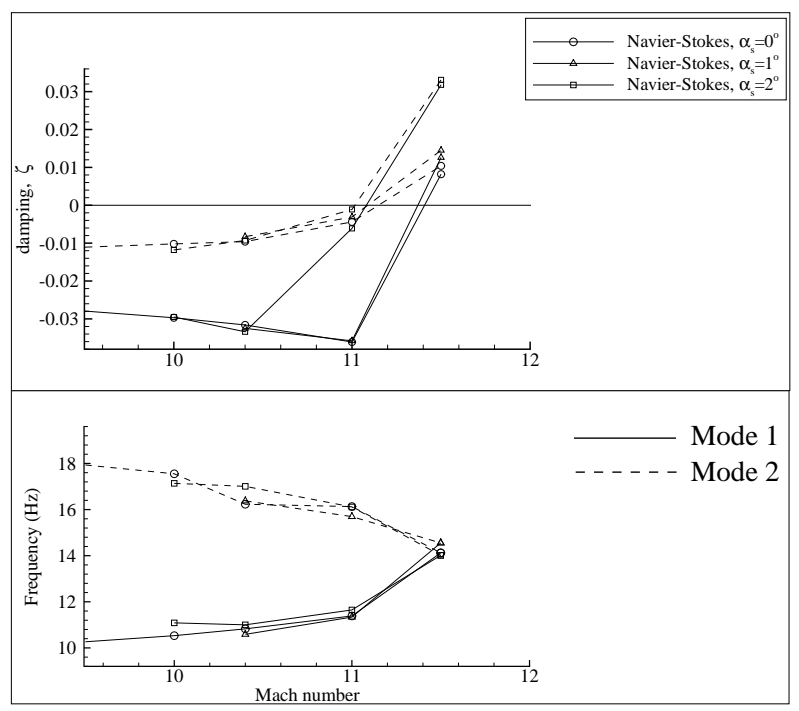

Figure 12: Effect of static angle of attack on the aeroelastic behavior of Configuration I at an altitude of 70,000 feet, using Navier-Stokes aerodynamics, $a=-0.2$.

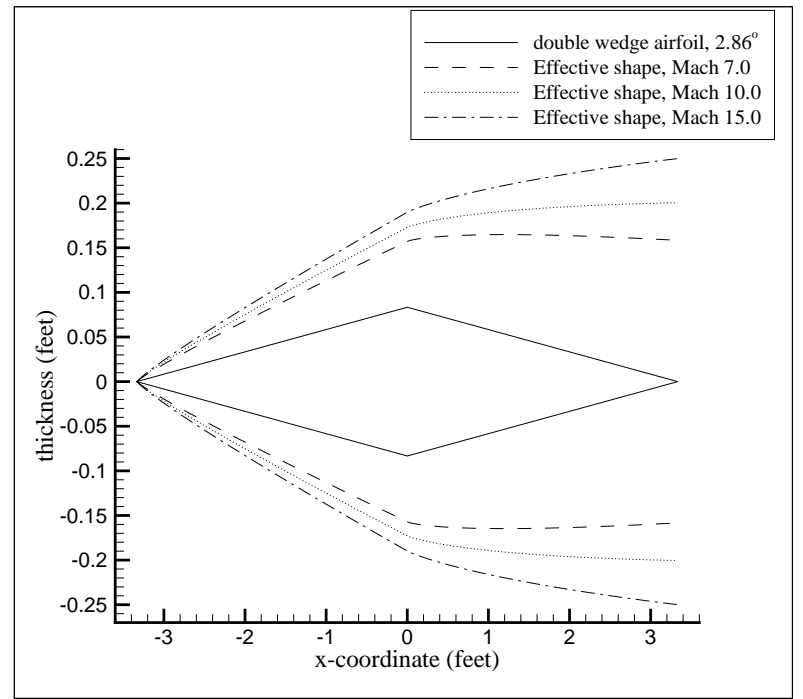

Figure 13: Effective shapes of Configuration I.

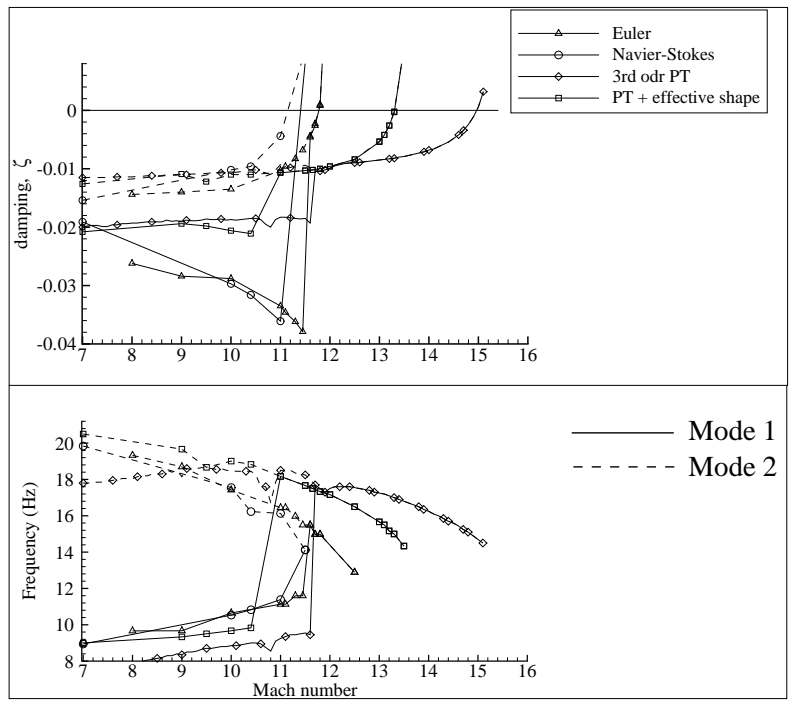

Figure 14: Comparison of aeroelastic results for Configuration I at an altitude of 70,000 feet, using Euler aerodynamics, Navier-Stokes aerodynamics, third-order piston theory and third-order piston theory with effective shapes, $a=-0.2$. 


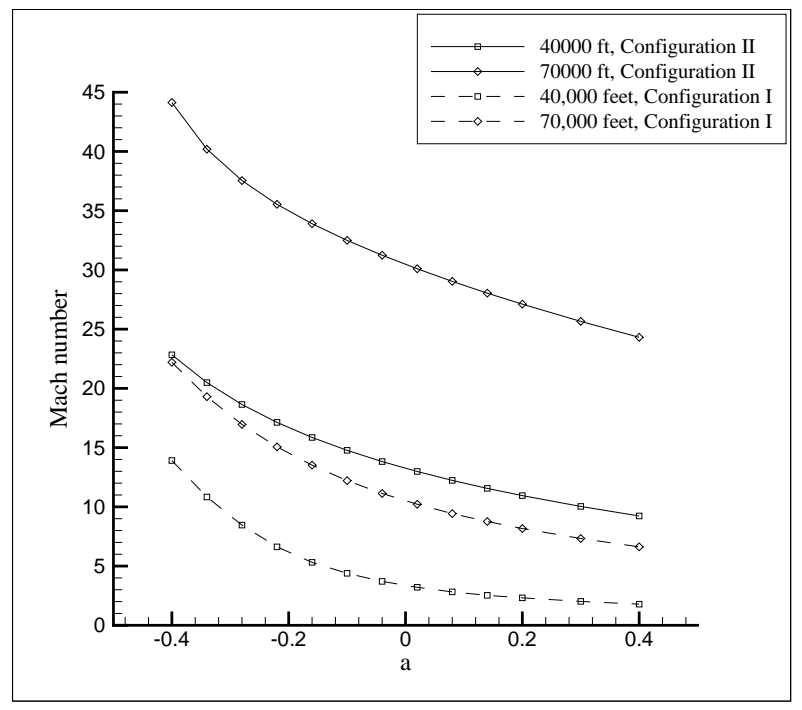

Figure 15: Flutter boundaries of Configurations I and II at zero angle of attack, obtained using thirdorder piston theory.

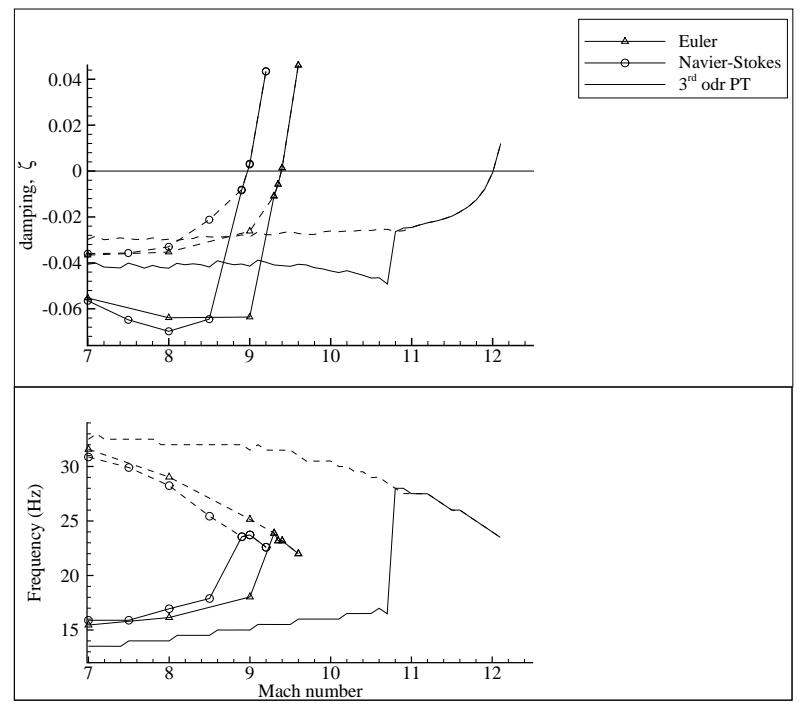

Figure 16: Comparison of aeroelastic results for Configuration II, at an altitude of 40,000 feet, unheated, $a=0.1$.

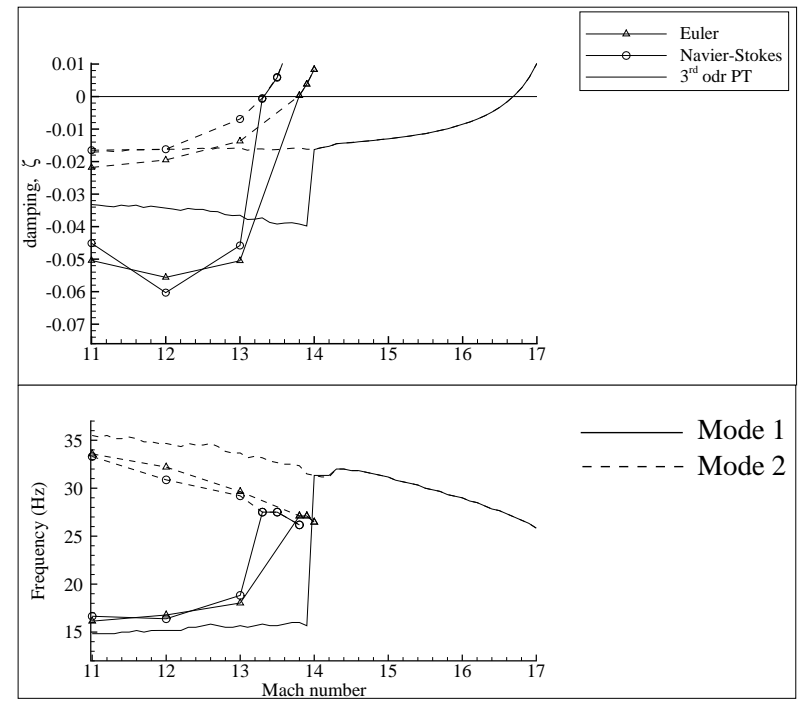

Figure 17: Comparison of aeroelastic results for Configuration II, at an altitude of 40,000 feet, unheated, $a=-0.2$. 


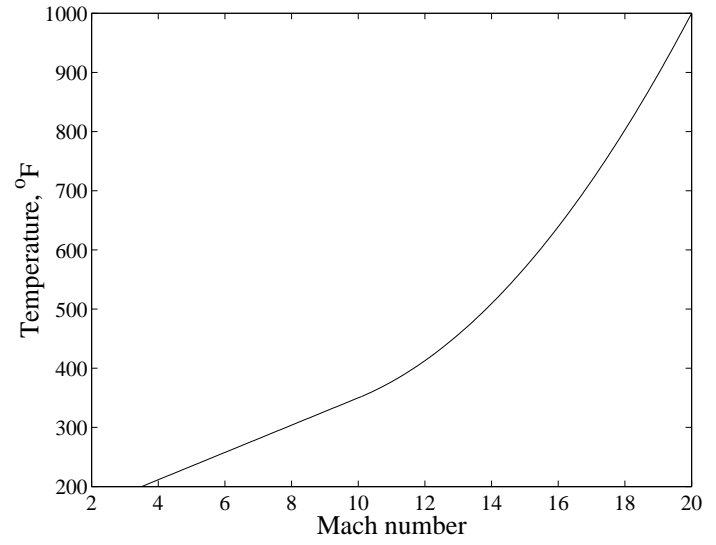

(a) Variation of temperature with Mach number.

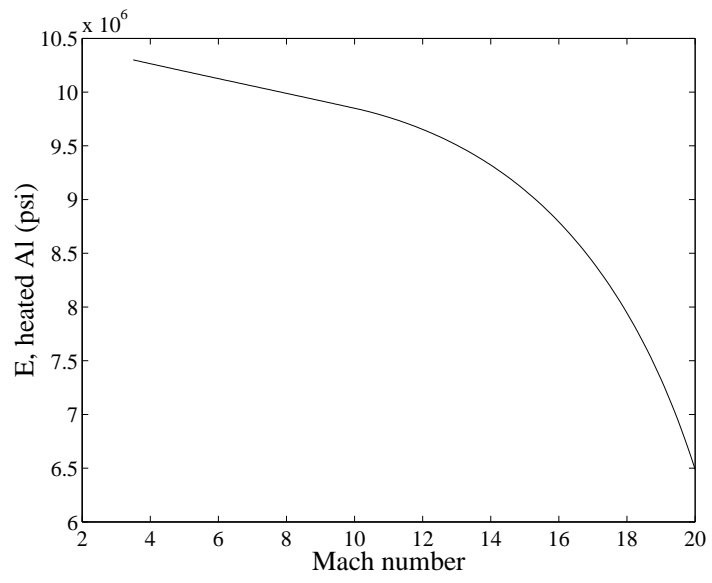

(b) Variation of the modulus of elasticity with Mach number.

Figure 18: Variation of temperature and dynamic modulus of elasticity of 2024-T3 Aluminum alloy with Mach number.

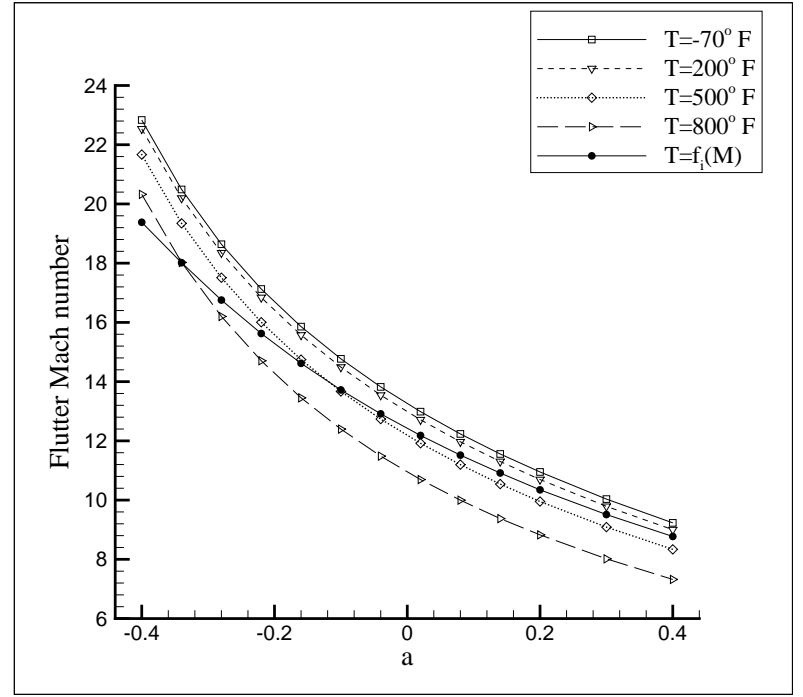

Figure 19: Comparison of aerothermoelastic results for Configuration II, using piston theory for different wing heating conditions.

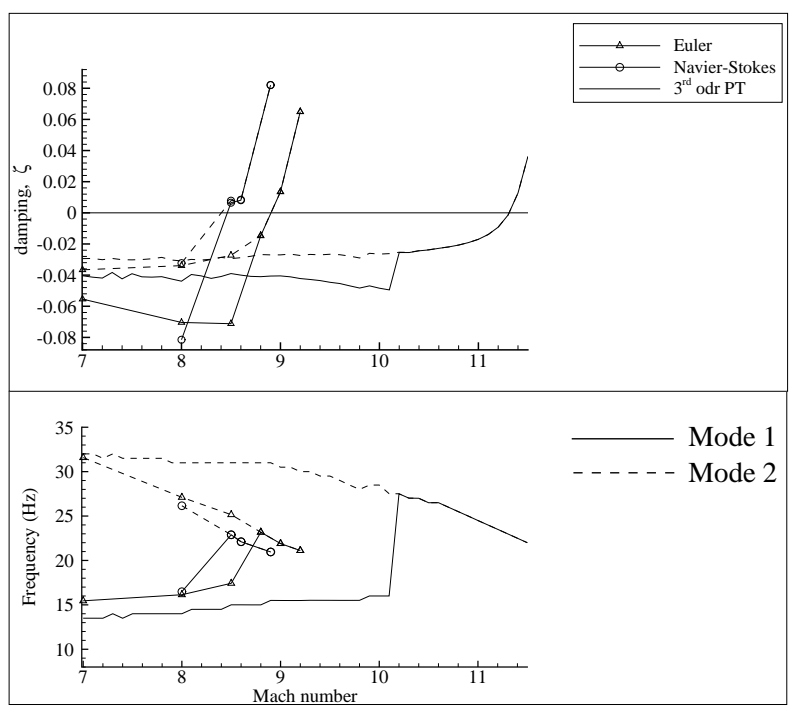

Figure 20: Comparison of aerothermoelastic results for Configuration II, at an altitude of 40,000 feet, heated, $a=0.1$. 


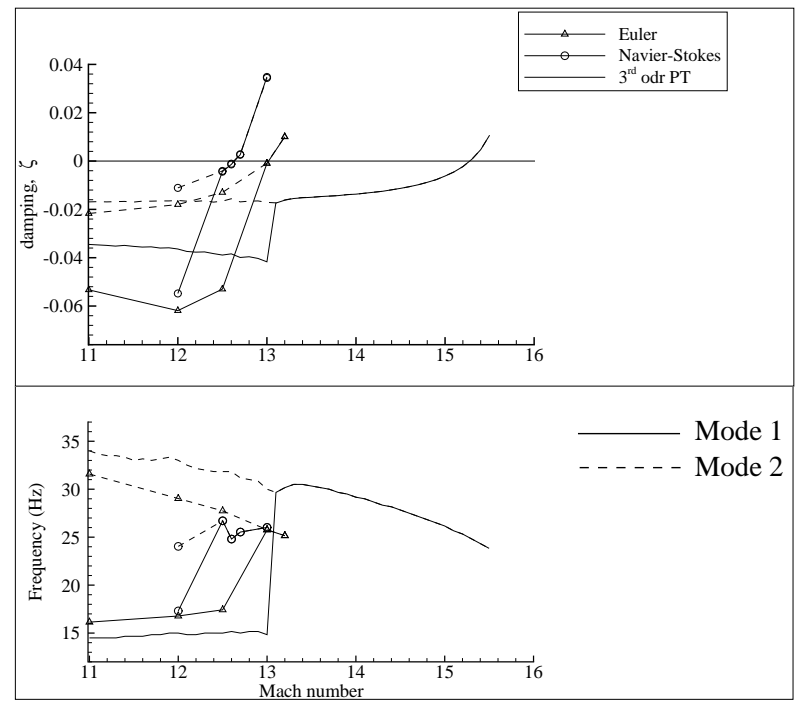

Figure 21: Comparison of aerothermoelastic results for Configuration II, at an altitude of 40,000 feet, heated, $a=-0.2$.

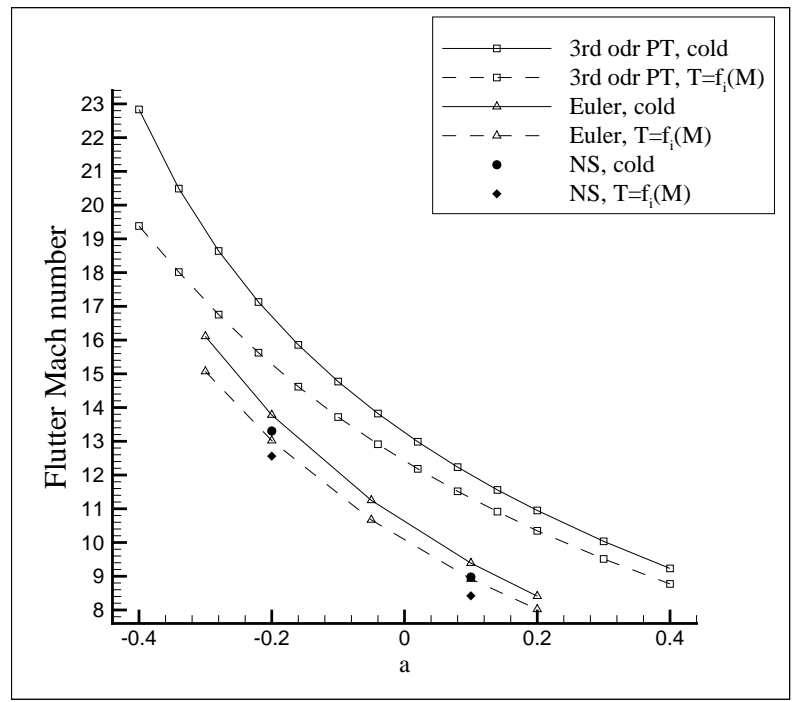

Figure 22: Comparison of flutter boundaries for Configuration II, heated and unheated wings, using third-order piston theory, Euler aerodynamics and Navier-Stokes aerodynamics.

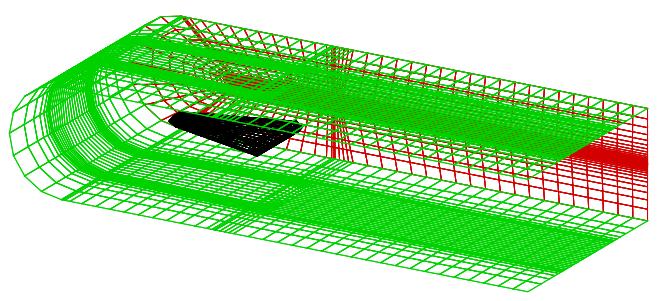

Figure 23: A representative view of the computational domain. 